\title{
Impact of Technology on Traditional Teaching - Learning Measures in The Era of Covid-19 Pandemic
}

\author{
Bhakti Narendra Raut \\ Department of Information Technology, Sonopant Dandekar College, Palghar, India; e-mail : rautbhakti8@gmail.com
}

\begin{abstract}
The period of 21stcentury is frequently respected as the period of Innovations and Technology. Today, Technology plays a significant part in our life. It is conceivable as it were through technology that distances are no more hindrances and training can be brought to the understudy's doorstep. The effect of innovation can be felt in each conceivable field and one such field is education. Instruction in its overall sense is a structure of learning in which the information, abilities and propensities from a gathering of individuals are changed from one age to next through instructing, preparing and research. Today, like never before, the job of instructive innovation in educating is of incredible significance in light of the utilization of data and correspondence advancements (ICT). Instructive innovation is a coordinated cycle of applying present day innovation to improve the nature of education. It is an efficient method of conceptualizing the execution and assessment of the instructive cycle, for example learning and educating furthermore, help with the use of current instructive educating methods. This paper features the significance of IT in educational areas, the effect of IT on study hall education, points of interest, and the detriments of IT.
\end{abstract}

Key Words: Pandemic, Education, Technology, M odern Classroom, M achine Learning.

SAM RIDDHI : A Journal of Physical Sciences, Engineering and Technology, (2021); DOI : 10.18090/samriddhi.v13iS1.21

\section{INTRODUCTION}

T he tInformation and Knowledge are the fundamental keys of acquiring the efficiency, rivalry, riches and solace in these days. Education is the focal point, everything being equal, and development. Technology has turned into the indispensable piece of our life in this time of 21st century.

This century has taught us a lot of new things and made us see a lot of unseen things. One of them is covid-19. It causes a sudden stop where everything is happening, as if dreaming. The disease swept the entire world in a very short time.A sudden lockdown occurred in most countries. And it all stopped. It started in our country India in M arch 2020 and we are still facing it. Schools and colleges were closed as people stopped leaving their homes. But it was not right to stop the education that needed time. As an alternative to this, the traditional
Corresponding Author : Bhakti Narendra Raut, Department of Information Technology, Sonopant Dandekar College, Palghar, India; e-mail : rautbhakti8@gmail.com

How to cite this article : Raut, B.N. (2021). Impact of Technology on Traditional Teaching - Learning M easures in The Era of Covid-19 Pandemic. SAM RIDDHI : A Journal of Physical Sciences, Engineering and Technology, Volume 13, Special Issue (1), 92-96.

\section{Source of support : Nil Conflict of interest : None}

teaching method was changed and during this period, education has been introduced completely online and it has been successful in some places.

To analyse the effects of technology in education online survey was conducted to collect the Data from the students of different branches. Secondary data is used from some websites to show the covid-19 infected people in India during Apr 2020 to Jan 2021. 
Impact of Technology on Traditional Teaching - Learning M easures in The Era of Covid-19 Pandemic

\section{POPULATION}

152 undergraduate students are selected as participants, In that total no of female are $n=89$ and male are $n=63$. The Participants selected are from different departments of the Institutions. Participants raged in age from 20-25.

\section{METHOD}

The research presented in this paper revolves around a research questions given as below.

RQ: Does the students want to adapt online learning for their academic growth?

The aim of this study is to determine whether the dependent variable (online learning) and the independent variable (academic growth) are associated. The data obtained from the students was analysed to address this research query.

The null hypothesis has indicated by $\mathrm{H}_{0} . \mathrm{H}_{0}$ states that there is no significant relationship between online learning and academic development.

$\mathrm{H}_{0}$ :There is no link between the online learning and online learning will help students' to get better results in their subjects.

$\mathrm{H}_{0}$ : There is no link between the online learning and online learning will students to understand the subject material more deeply.

$\mathrm{H}_{0}$ : There is no link between the online learningand online learning makes completing work in students' subjects more convenient.

$\mathrm{H}_{0}$ :There is no link between the online learningand online learning motivates students' to explore many topics they may not have seen before.

The alternative hypothesis has indicated by $\mathrm{H}_{1}$ and it proposes that there is a correlation between online learning and academic growth in students.

$\mathrm{H}_{1}$ :There is correlation between the online learningand online learning will help students' to get better results in their subjects.

$\mathrm{H}_{1}$ : There is correlation between the online learning and online learning will help students to understand the subject material more deeply.

$\mathrm{H}_{1}$ : There is correlation between the online learningand online learning makes completing work in students' subjects more convenient.
$\mathrm{H}_{1}$ :There is correlation between the online learningand online learning motivates students' to explore many topics they may not have seen before.

\section{Data COllection}

To show the rapid growth of covid-19 infection throughout the country, secondary data is used in this paper. Primary data is used to identify the positive and negative impact of technology during pandemic on Teaching-Learning measures. An online survey was conducted through Google form to get the answers of few questions from pupils. Age bracket 20-25 is decided to collect the data from various students of different branches. Total 152 samples were collected to analyze the data.

\section{RESULT}

Participant were asked few questions through an online survey. Answers of those questions are collected in an excel file and that file has been used for further analysis.

\section{Graphical Representation of Covid-19 Infection in India}

This study is based on primary as well as secondary data. Secondary data is used to show the graphical representation of covid-19 infected people. A graph shown in fig. 1 is generated using google colab and python is used to plot the line graph. Data from April 2020 to Jan 2021 have been used to plot this graph. It is showing us that infection was spreading across the nation from April 2020. In the month of September and October it reaches to the highest peak and then coming down after November and In the December and Jan the overall ratio is coming down.

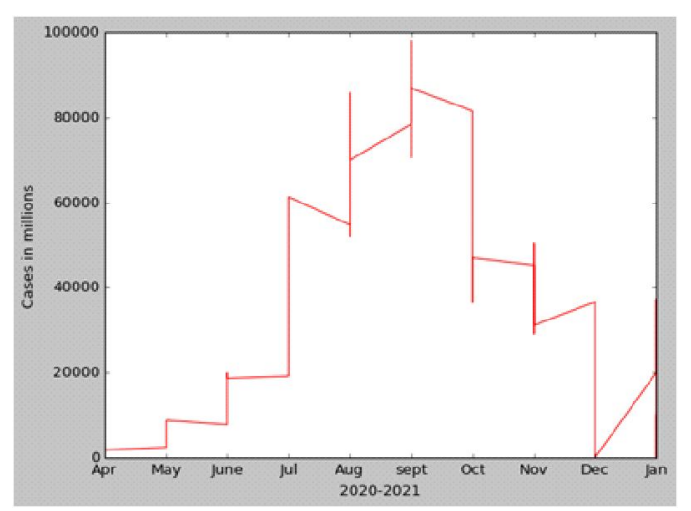

Figure 1: Growth Of Covid-19 Infection 
Impact of Technology on Traditional Teaching - Learning M easures in The Era of Covid-19 Pandemic

During this entire period we faced lot of ups and downs in various sector. Education is one of them. We will find out the impact of Pandemic on Teaching-Learning measure in the section $\mathrm{B}$.

\section{Data Analysis and Interpretation of the results}

RQ: Does the students want to adapt online learning for their academic growth?

We have determined the correlation between both variables for each module separatelyto answer this research question, which is as follows:

RQ 1.1: Is there any relation between the online learningand online learning will help students' to get better results in their subjects.

The null hypothesis has indicated by $\mathrm{H}_{0}$ and the alternative hypothesis by $\mathrm{H}_{1}$ are as below:

$\mathrm{H}_{0}$ : There is no relation between the online learningand online learning will help students' to get better results in their subjects.

$\mathrm{H}_{1}$ : There is a correlation between the online learningand online learning will help students' to get better results in their subjects.

The data presented in Figure 2.has been graphically analysed using the bar graphs. It shows that approximately 120 students think that online learning will help them to get better results in their subjects. in that approximately 30 students strongly agree with this. Whereas approximately 30 students think that there is no effect of online learning on their results. $\sim 10-15$ students think that traditional learning is better for their results.

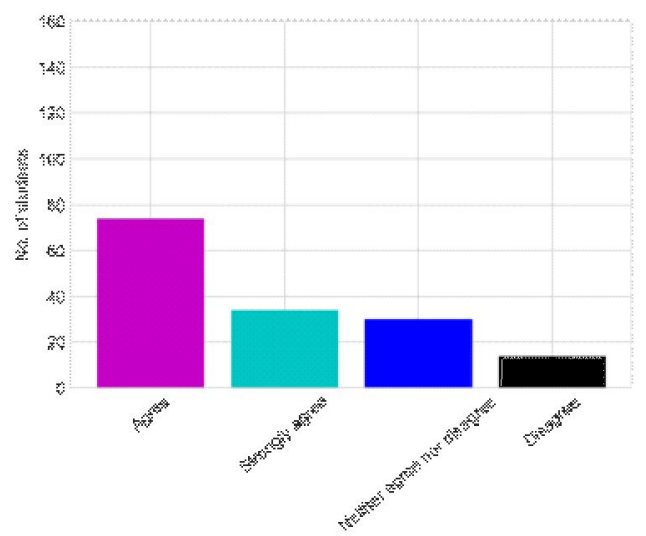

Figure 2: Online learning $\&$ high result score
Normalisation of data has been performed on the online learning (students wish to integrate more technology in their education) and online learning will help students' to get better results in their subjects to find out what the Pearson correlation coefficient is. The findings reveal a statistically significant positive association between the two variables online learning (students wish to integrate more technology in their education) and online learning will help students' to get better results in their subjects;.$(-1<=r<=1$; where -1 indicates a strong negative correlation, 0 indicates no correlation and 1 indicates a strong positive correlation). Value of For the 152 cases, the Pearson correlation coefficient is $r=0.964$. As a result, there is a moderately positive relationship between the online learning (students wish to integrate more technology in their education) and online learning will help students' to get better results in their subjects.

RQ 1.2: Is there any correlation between the online learningand online learning help students to understand the subject material more deeply?

The alternative hypothesis has stated by $\mathrm{H}_{1}$ and the null hypothesis by $\mathrm{H}_{0}$ is as below:

$\mathrm{H}_{0}$ : There is no relation between the online learningand online learning help students to understand the subject material more deeply.

$\mathrm{H}_{1}$ : There is a correlation between the online learningand online learning help students to understand the subject material more deeply.

The data presented in Figure 3.has been graphically analysed using the bar graphs that Shows that approx. 110 students think that online learning will help them to understand the subject material more deeply. In that $\sim 30$ students strongly agree with this. Where as approx. $\sim 30$ students think that there is no effect of online learning on subject material understanding. $12-15$ students think that traditional learning is better for subject material understanding. 


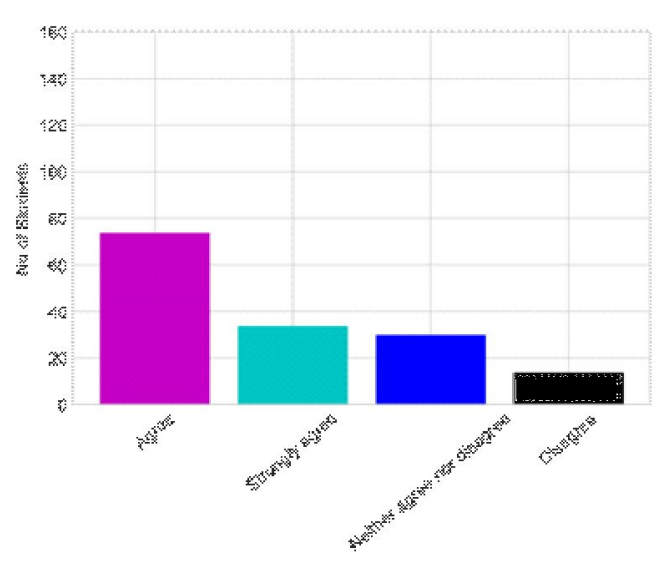

Figure 3: Online learning \& understanding of subject material

The data normalisation has been performed on the online learning (students wish to integrate more technology in their education) and online learning help students to understand the subject material more deeply for calculating Pearson's correlation coefficient. The results shows that there is a statistically significant positive correlation between the online learning (students wish to integrate more technology in their education) and online learning help students to understand the subject material more deeply; Value of Pearson's correlation coefficient is $r=0.923$ for the 152 cases. So, there is a moderate positive correlation between the online learning (students wish to integrate more technology in their education) and online learning help students to understand the subject material more deeply.

RQ 1.3: Is there any relation between the online learningand online education to complete subject related work?

The alternative hypothesis has stated by $\mathrm{H}_{1}$ and the null hypothesis by $\mathrm{H}_{0}$ are as below:

$\mathrm{H}_{0}$ : There is no relation between the online learningand online education to complete subject related work.

$\mathrm{H}_{1}$ : There is a relation between the online learningand online education to complete subject related work.

The data presented in Figure 4. has been graphically analysed using the bar graphs which Shows that approx. 115 students think that online learning will help them to complete subject related work more conveniently. In that $\sim 35$ students strongly agree with this. Whereas approx. $\sim 35$ students think that there is no effect of online learning to complete subject related work more conveniently. $\sim 5-7$ students think that traditional learning is better for to completing subject related work more conveniently.

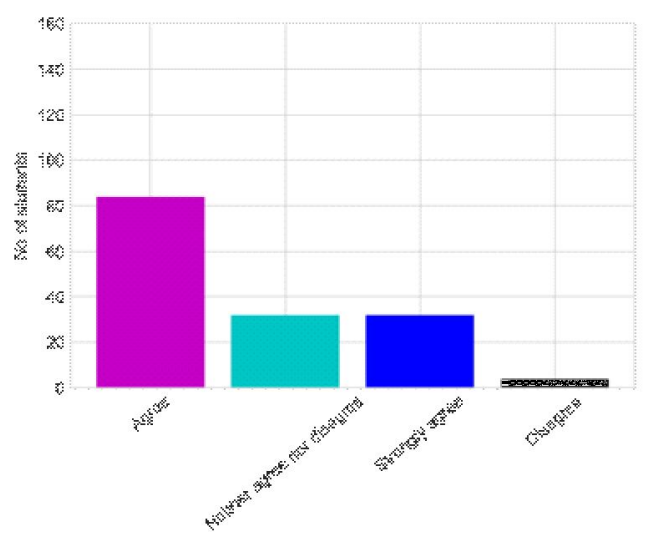

Figure 4: Online education to complete subject related work

The data normalisation has been performed on the online learning (students wish to integrate more technology in their education) and online education to complete subject related work to calculate the Pearson's correlation coefficient. The results show that there is a statistically significant positive correlation between the online learning (students wish to integrate more technology in their education) and online education to complete subject related work; value of Pearson's correlation coefficient is $r=0.914$ for the 152 cases. Therefore, overall, there is a moderate positive correlation between the online learning (students wish to integrate more technology in their education) and online education to complete subject related work.

RQ 1.4:Is there any correlation between the online learningand online learning motivates students' to explore more topics they may not have seen before?

The alternative hypothesis $\left(H_{1}\right)$ and the null hypothesis $\left(\mathrm{H}_{0}\right)$ are:

$\mathrm{H}_{0}$ : There is no correlation between the online learningand online learning motivates students' to explore more topics they may not have seen before. $\mathrm{H}_{1}$ : There is a correlation between the online learningand online learning motivates students' to explore more topics they may not have seen before. 
Impact of Technology on Traditional Teaching - Learning M easures in The Era of Covid-19 Pandemic

The data presented in Figure 5. has been graphically analysed using the bar graphs which Shows that approx. $\sim 70$ students think that online learning motivates them to explore more topics they may not have seen before. In that $\sim 40$ students strongly agree with this. Where as $\sim 30$ students think that there is no effect of online learning on motivation level. $10-15$ students think that traditional learning is better for to explore more topics they may not have seen before.

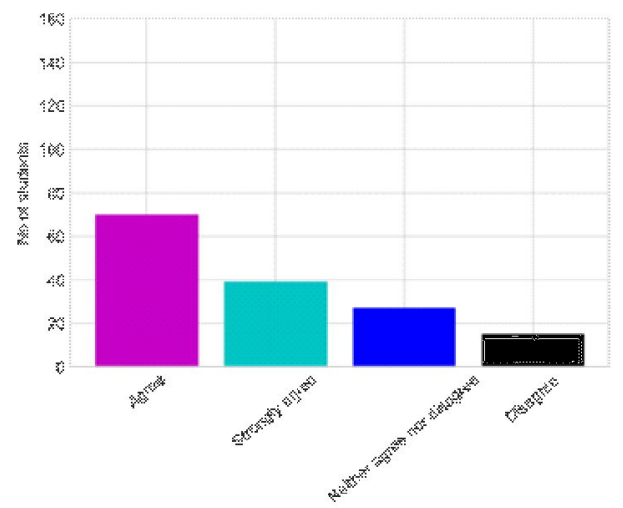

Figure 5: Online learning $\&$ M otivation for exploring more topics

The data normalisation has been performed on the online learning (students wish to integrate more technology in their education) and online learning motivates students' to explore more topics they may not have seen before to find out what the Pearson correlation coefficient is. The findings reveal a statistically significant positive association between the online learning (students wish to integrate more technology in their education) and online learning motivates students' to explore more topics they may not have seen before; For the 152 cases, value of Pearson's correlation coefficient is $r=0.966$. As a result, there is a moderate positive association between the two variables.
Therefore, there is a moderate positive correlation between the online learning (students wish to integrate more technology in their education) and online learning motivates students' to explore more topics they may not have seen before.

\section{DISCUSSION}

This study has found that there is a positive correlation between online learning and online learning will help students' to get better results in their subjects, online learning and online learning will help students to understand the subject material more deeply, online learning and online learning makes completing work in students' subjects more convenient, online learning and online learning motivates students' to explore many topics they may not have seen before.

Therefore the main findings indicate that Students highly wants to adapt online learning in their education. They think online learning is very beneficial for them. Thus we can say that our traditional learning measure are somewhat affected because of online learning system during covid-19 pandemic.

\section{REFERENCES}

[1] Sandeep Chowdhry, Sieler K., \&Alwis. L, A Study of the Impact of Technology -Enhanced Learning on Student Academic Performance, Journal of Perspectives in Applied Academic Practice,(2014).

[2] Jena Pravat Kumar, Impact of Pandemic COVID-19 on Education in India, International Journal of Current Research (IJCR), Vol-12, Issue-7, P.1258212586 (2020), (2020).

[3] Mishra Lokanath, Gupta Tushar and Shree Abha. Online teaching-learning in higher education during lockdown period of COVID-19 pandemic, Volume 1, (3 September 2020).

[4] R. Raja*, P. C. Nagasubramani, Impact of modern technology in education, Journal of Applied and Advanced Research, 2018.

[5] Shah, Why does writing make us smart ? , (2011, July 16) 